\title{
Embracing electronic learning in medical education during COVID-19 pandemic
}

\author{
Soni Bista ${ }^{1 *}\left(\mathbb{D}\right.$, Rupesh Shingh Basnyat ${ }^{2}$, Rebicca Ranjit ${ }^{1}$ (iD), Nuwadatta Subedi ${ }^{3}$
}

'Department of Periodontology and Oral Implantology, College of Dental Surgery, Gandaki Medical College Teaching Hospital and Research Centre Pvt. Ltd, Pokhara, Nepal, ${ }^{2}$ Department of Obstetrics and Gynaecology, Shishuwa Hospital, Pokhara, Nepal, ${ }^{3}$ Department of Forensic Medicine, Gandaki Medical College Teaching Hospital and Research Centre Pvt. Ltd, Pokhara, Nepal.

\begin{abstract}
Medical education is considered as a very significant strategy ensuring good quality in academics and health care. Currently, medical education across the world has been experiencing a major obstruction as a consequence of the novel coronavirus disease pandemic. At the same time, the rapid use of emergent technologies to maintain effective teaching and learning has become an essential component for transformative changes and the future of medical education. In this paper, we discuss the role of e-learning in medical education by outlining its components, effectiveness, barriers, all the pros and cons and future of implementation of such technology. The intention of this article is to inform all medical educators and students across the world on how the technological changes even after the pandemic can have a positive impact on medical education.
\end{abstract}

Keywords: COVID-19, distance learning, electronic learning, medical education, online classes.

\section{*Correspondence:}

Dr. Soni Bista

Department of Periodontology and Oral Implantology, College of Dental Surgery, Gandaki Medical College, Pokhara, Nepal. Email: sonibista12345@gmail.com

Phone: +977-9868841410

Submitted: March 25, 2021

Accepted: May 31, 2021

To cite: Bista S, Basnyat RS, Ranjit R, Subedi $\mathrm{N}$. Embracing electronic learning in medical education during COVID-19 pandemic. JGMC Nepal. 2021;14(1):68-72.

DOI: $10.3126 /$ jgmcn.v14i1.35997

\section{BACKGROUND}

The outbreak of novel coronavirus (COVID-19) pandemic has obstructed medical education globally by forcing students to stay away from the schools and colleges in order to prevent the potential spread of the virus. ${ }^{1}$ Most of the medical schools have quickly shifted from face-to-face learning to the online classes with virtual learning systems. With the recent rapid advances in new learning technologies and the wide availability of the Internet, electronic learning has assumed an increasingly important role in medical education.

"Electronic learning (e-learning) can be defined as the use of electronic technology and media to deliver, support and enhance both learning and teaching and involves communication between learners and teachers utilizing online content."2 The term e-learning has been used interchangeably with terms such as online learning, distance learning, computer-assisted learning, web-based learning and digital literacy. It serves as an effective alternative to traditional education, improving the quality and quantity of educational medical and dental programs. ${ }^{3}$ Indeed, it has become an integral part of medical education..$^{4,5} \mathrm{~A}$ wide range of studies have been conducted to assess the feasibility and delivery of e-learning in both undergraduate ${ }^{6,7}$ and postgraduate levels. ${ }^{2}$ Furthermore, many authors have focused primarily on evaluating students' satisfaction ${ }^{8,9}$ and analyzed the influence of e-learning on the acquisition of knowledge or skills. ${ }^{10,11}$ However, more studies are still needed to prove the impact of e-learning.

Components of e-learning: Once contents on e-learning are devel- 
oped, it must be managed, delivered, and standardized.

Learning contents imitate instructional materials assembled following specific learning objectives, which are then used to build larger educational materials such as lessons, modules, or complete courses to meet the requirements of a specified curriculum. ${ }^{12}$ Examples are tutorials, casebased learning, hypermedia, etc. Medical educators use instructional design and pedagogical principles to produce learning objects and instructional materials to the learners.

Content management is carried out by storing, indexing, tracking and cataloging to make e-learning content available to learners. Examples are portals, digital libraries, learning-management systems, search engines, and ePortfolios. Learning management systems familiar in medical education are WebCT $\AA$ or Blackboard $\AA$ which provides an online proprietary virtual learning environment system. ${ }^{1}$ Content delivery can be either synchronous or asynchronous: ${ }^{14}$

Synchronous delivery: It refers to real-time, teacher led e-learning through tele-conferencing or Internet chat forums. Examples include Macromedia and Breeze applicable in medical education. Connecting learners from distant sites to live training sessions; creating opportunities for trainers and participants to interact in real time; fostering peer-to-peer feedback; interacting with learning resources such as lecture notes or simulated cases are some of the advantages possessed by such delivery systems.

Asynchronous e-learning: It can be carried out via email or weblogs, where delivery and receipt of information are not simultaneous. It offers flexibility and accessibility; however, it loses on interaction and connection in the trade-off. It is cost effective and can train thousands of learners at once. Some examples include online courses, blogs and pre-recorded webinars.

Standardization of contents are important for the creation of new e-learning materials. Such standards promote compatibility and usability of products across many computer systems, facilitating the widespread use of e-learning materials. In medical education, MedBiquitous, is working to develop the most well-known set of standards i.e. Sharable Content Object Reference Model (SCORM). ${ }^{15}$

Modes of e-learning: There have been two common modes of e-learning:16 1) Distance learning: Uses information technologies to deliver instruction to learners who are at remote locations from a central site. 2) Computer assisted learning: Uses computers to aid in the delivery of stand- alone multimedia packages for learning and teaching.

E-application tools: The popular tools used by the medical educators includes: ${ }^{1}$

- Google: It provides unrestricted access to its basic features without any charges but applies a monthly subscription charge for the advanced one (Google Hangouts and Google meet).

- Microsoft: It offers limited duration free trial at various countries of its highest tier of Microsoft Teams to enable institutions to function swiftly.

- Zoom: It possesses massive popularity in this crisis period. It raised controversies too, but the company is rolling newer versions to overcome the issues encountered by users.

- Tencent's WeChat Work or Alibaba-owned DingTalk: These are cloud meeting and team collaboration tools for facilitating remote teaching and learning

- GoToMeeting and GoToWebinar of 'LogMeIn': These are video conferencing tools which are utilized broadly.

- Webex tool by 'Cisco': It is invigorating to suitably assist institutions round the clock in more than forty countries.

Effectiveness of e-learning: Some aspects of e-learning which have been consistently explored are as follows:

1. Usefulness: Gibbons et $\mathrm{al}^{17}$ reported that learners using computer-based instruction learned more efficiently and demonstrated better retention compared to traditional learning methods. Similar findings were revealed by a recent review of the web- based learning literature in diverse medical education contexts. ${ }^{18}$

2. Cost-effectiveness: Cost-effectiveness are related to reduced training time, travel costs, reduced institutional infrastructure, labor costs. ${ }^{17}$ Chumley-Jones et $\mathrm{al}^{18}$ found the cost of printing and distribution of educational materials is less during web-based learning.

3. Learner satisfaction: Learners' satisfaction rates increase with e-learning compared to traditional learning, along with perceived ease of use and access, navigation, interactivity, and user-friendly interface design. Interestingly, students do not see e-learning as replacing traditional instructor-led training but as a complement to it, forming part of a blended-learning strategy. ${ }^{17,18}$

4. Learning outcomes and performance improvement: 
Learning outcomes includes assessment of learners' knowledge, attitudes, and skills. Performance improvement relates to changes in practice behaviors which is a direct result of the newly acquired knowledge, attitudes, and skills. In a study conducted by Curran et $\mathrm{al},{ }^{19}$ which examined CME-related e-learning studies, $81 \%$ of the reviewed studies included evaluation of learner's satisfaction, followed by $52 \%$ targeting learning outcomes and 7\% evaluating student performance change in clinical practice.

\section{Barriers on online learning with solutions:}

1. Lack of skills: Online educators may have insufficient computer and typing skills together with poor infrastructure, which hinders their willingness or ability to engage with the development or delivery of online learning. ${ }^{20}$ This can be solved by implementing workshops for online educators so that they can learn new skills and gain familiarity with the tools. Perlman et $\mathrm{al}^{21}$ argued the importance of providing faculty with the necessary skills via training provided on the use of the ePortfolio tool.

2. Insufficient time: Inadequate time to master and implement the online learning tools can be seen as a significant barrier. Lack of time appears to be linked with lack of incentives to engage with online or e-learning. Thus, it is crucial for educators to afford the time for becoming familiar with digital tools to learn concepts and reflect it on their practices. $^{20}$

3. Poor infrastructure: This is a barrier typically seen within faculties in low-medium income countries. ${ }^{22}$ These countries have technological limitations such as lack of email, intermittent internet access, etc. Bediang et $\mathrm{al}^{22}$ highlighted the issues faced by a low-income country (Cameroon) because of poor internet connectivity, $\mathrm{Wi}-\mathrm{Fi}$, and access to physical infrastructure. In order to remove such barriers, the cost of establishing the correct infrastructure should be implemented. ${ }^{23}$

4. Poor communication: Where there was a lack of institutional support and limited direction as to how tools or programs would be implemented, implementation was rarely successful. ${ }^{24}$ Therefore, an institutional strategy is required which facilitates the implementation of key skills and the adoption of methodologies by faculty when implementing online learning. ${ }^{22}$

5. Negative attitude: Negative attitude amongst educators in engaging with new technologies and tools can be seen as a barrier to the development and implementation of online learning. Maintaining a positive attitude for the time-consuming e-learning tools and technologies can be quite problematic. Educators involved in one study noted that it was important to try to maintain a positive attitude towards learning new approaches. ${ }^{20}$

\section{Advantages or e-learning: ${ }^{14,25}$}

- Acquisition of knowledge from various forms of media and e-textbooks

- As a teaching aid in the development of professionalism

- Improves learning delivery

- Increased accessibility of educational materials

- Content can be readily updated than conventional written data

- Content is standardized and distribution are enhanced

- Outcomes assessment can be made

- Students can control the pace, timing and level of their interaction

- Opportunity to work with new and emerging cutting-edge technologies.

- Online instructors can teach from anywhere in the world as long as they have an internet connection.

- There is no class time missed due to illness, public holidays or even during crisis, lockdown

\section{Disadvantages of e-learning: ${ }^{26}$}

- It is difficult to assess the level of student learning and to regularly communicate with them without being face to-face.

- Students require constant feedback and clarifications on difficult concepts which can be very time consuming for the faculties.

- Technical difficulties and problems associated with modern technology range from downloading errors, issues with installation, login problems, problems with audio and video, and so on.

- Sometimes, online content is all theoretical and does not let students practice and learn effectively.

- Distractions, frustration, anxiety \& confusion for both educators and learners

- Lack of personal/physical attention

- Practical skills cannot be implemented 
Future implications: The era of COVID-19 pandemic seems to be a crucial turn as this has compelled us to transform ways in teaching and learning. During this inevitable transformation, a creative thinking towards development of the novel models in medical education is required. The future is unpredictable but in order to maintain the sustainability of medical education, we should consider transformation from now. ${ }^{20}$ Without an evolving knowledge regarding efficient application of e-learning design, the gap between the use of technology and deployment of e-learning in training settings will continue to widen. ${ }^{27}$

Therefore, the future of e-learning in medical education should be directed towards:

- Creation of flexible infrastructure which will enable access to e-Learning by all students and faculties.

- Improvement of digital literacy amongst academic population

- Rapid adoption of emerging communication, simulation, and information technology in undergraduate, graduate, and continuing medical education

- A national call for competency-based, patient outcome-oriented training across the continuum of education

- Development of "Lifelong learning way of life" to upgrade online educators and learners ${ }^{28}$

\section{CONCLUSIONS}

Electronic learning is a current trend used by many countries and is spreading fast throughout the rest of the world. Whole world is fighting in this pandemic for best solutions in the development of novel ideas of electronic learning for medical schools, which can efficiently enable the futuristic clinicians to meticulously provide patient care and serve the communities in their best capacity. Thus, this paper intends to present a general overview about electronic learning with a focus on its role in medical education. We hope this will be just a starting ground to our attempts of improvement of our medical education system.

\section{REFERENCES}

1. Potaliya P, Ghatak S. New Trends in Medical Education During and Post COVID-19 Pandemic. European Journal of Medical and Health Sciences. 2020;2(3). DOI:10.24018/ ejmed.2020.2.3.275

2. Howlett D, Vincent T, Gainsborough N, Fairclough J, Taylor $\mathrm{N}$, Cohen J, et al. Integration of a Case-Based Online Module into an Undergraduate Curriculum: what is involved and is it effective? E-Learning and Digital Media. 2009;6(4):37284. DOI: 10.2304/elea.2009.6.4.372

3. Lahti $M$, Hätönen $H$, Välimäki $M$. Impact of e-learning on nurses' and student nurses' knowledge, skills, and satisfaction: a systematic review and meta-analysis. International journal of nursing studies. 2014;51(1):13649. DOI: 10.1016/j.ijnurstu.2012.12.017 PMID: 23384695.

4. Gray K, Tobin J. Introducing an online community into a clinical education setting: a pilot study of student and staff engagement and outcomes using blended learning. BMC medical education. 2010 Dec 1;10(1):6 DOI: 10.1186/14726920-10-6 PMID: 20100354 PMCID: PMC2828452.

5. HullP,ChaudryA,PrasthoferA,PattisonG.Optimalsequencing of bedside teaching and computer-based learning: a randomised trial. Medical education. 2009;43(2):108-12. DOI: 10.1111/j.1365-2923.2008.03261.x PMID: 19161479.

6. Greenhalgh T. Computer assisted learning in undergraduate medical education. Bmj. 2001;322(7277):40-4. DOI: $10.1136 /$ bmj.322.7277.40 PMCID: PMC1119309 PMID: 11141156.

7. Harden RM, Hart IR. An international virtual medical school (IVIMEDS): thefuture formedical education? Medical teacher. 2002;24(3):261-7. DOI: 10.1080/01421590220141008 PMID: 12098412.

8. Citak M, Calafi A, Kendoff D, Kupka T, Haasper C, Behrends $M$, et al. An internet based learning tool in orthopaedic surgery: preliminary experiences and results. Technology and Health Care. 2009;17(2):141-8. DOI: 10.3233/THC2009-0539

9. Gesundheit N, Brutlag P, Youngblood P, Gunning WT, Zary $\mathrm{N}$, Fors U. The use of virtual patients to assess the clinical skills and reasoning of medical students: initial insights on student acceptance. Medical teacher. 2009;31(8):739-42. DOI: 10.1080/01421590903126489 PMID: 19811211.

10. Heye T, Kurz P, Eiers M, Kauffmann GW, Schipp A. A radiological case collection with interactive character as a new element in the education of medical students. Rofo: Fortschritte auf dem Gebiete der Rontgenstrahlen und der Nuklearmedizin. 2008;180(4):337-44. DOI: 10.1055/s2008-1027217 PMID: 18499910.

11. Gormley GJ, Collins K, Boohan M, Bickle IC, Stevenson M. Is there a place for e-learning in clinical skills? A survey of undergraduate medical students' experiences and attitudes. Medical teacher. 2009;31(1):e6-12. DOI: 10.1080/01421590802334317 PMID: 19253150.

12. Littlejohn A, editor. Reusing online resources: a sustainable approach to e-learning. Psychology Press; 2003;1-6. DOI: 10.5334/2003-1-reuse-01 
13. Johnson CE, Hurtubise LC, Castrop J, French G, Groner $J$, Ladinsky $M$, et al. Learning management systems: technology to measure the medical knowledge competency of the ACGME. Medical education. 2004;38(6):599-608. DOI: $10.1111 / \mathrm{j} .1365-2929.2004 .01792 . x$

14. Ruiz JG, Mintzer MJ, Leipzig RM. The Impact of e-Learning in Medical Education. Academic Medicine. 2006;81(3):207-12. DOI: $10.1097 / 00001888-200603000-00002$

15. The MedBiquitous Consortium: Enabling Collaboration for Healthcare Education. http://www.medbiq.org. Accessed 22 September 2020. MedBiquitous, Baltimore, MD 2005.

16. Ward JP, Gordon J, Field MJ, Lehmann HP. Communication and information technology in medical education. The Lancet. 2001;357(9258):792-6. DOI: 10.1016/S01406736(00)04173-8 PMID: 11253986.

17. Gibbons A, Fairweather P. Computer-based instruction. In: Tobias S, Fletcher J (eds). Training \& Retraining: A Handbook for Business, Industry, Government, and the Military. New York: Macmillan Reference USA, 2000:410-42.

18. Chumley-Jones HS, Dobbie A, Alford CL. Web-based learning: sound educational method or hype? A review of the evaluation literature. Acad Med. 2002;77 (10 suppl):S86-S93.

19. Curran VR, Fleet L. A review of evaluation outcomes of web-based continuing medical education. Med Educ. 2005;39(6):561-7. DOI: 10.1111/j.1365-2929.2005.02173.x PMID: 15910431.

20. Dyrbye L, Cumyn A, Day H, Heflin M. A qualitative study of physicians' experiences with online learning in a master's degree program: benefits, challenges, and proposed solutions. Med Teach. 2009;31(2):e40-6. DOI: $10.1080 / 01421590802366129$

21. Perlman R, Christner J, Ross P, Lypson M. A successful faculty development program for implementing a sociocultural ePortfolio assessment tool. Aca Med. 2014;89(2):257-62.
DOI: 10.1097/ACM.0000000000000120

22. Bediang G, Stoll B, Geissbuhler A, Klohn AM, Stuckelberger A, Nko'o $S$, et al. Computer literacy and E-learning perception in Cameroon: the case of Yaounde Faculty of Medicine and Biomedical Sciences. BMC medical education. 2013;13:57. DOI:10.1186/1472-6920-13-57

23. Maloney S, Haas R, Keating J, Molloy E, Jolly B, Sims J. Breakeven, cost benefit, cost effectiveness, and willingness to pay for web based versus face-to-face education delivery for health professionals. J Med Internet Res. 2012;14(2):e47. DOI: 10.2196/jmir.2040 PMID: 22469659.

24. Bury J, Martin L, Roberts S. Achieving change through mutual development: supported online learning and the evolving roles of health and information professionals. Health Inf Libr J. 2006;23(1):22-31. DOI: 10.1111/j.14711842.2006.00677.x PMID: 17206993.

25. Wilson AS, Goodall JE, Ambrosini G, Carruthers DM, Chan $\mathrm{H}$, Ong SG, et al. Development of an Interactive Learning Tool for Teaching Rheumatology - a simulated clinical case studies programme, Rheumatology. 2006;45:1158-61. DOI:10.1093/rheumatology/kel077

26. Esani M. Moving from face-to-face to online teaching. Clin Lab Sci. 2010;23(3):187-90. PMID: 20734893. DOI: 10.29074/ ascls.23.3.187Kim S. The future of e-learning in medical education: current trend and future opportunity. J Educ Eval Health Prof. 2006;3:3. DOI: 10.3352/jeehp.2006.3.3 PMID: 19223995.

27. Kim S. The future of e-learning in medical education: current trend and future opportunity. J Educ Eval Health Prof. 2006;3:3. DOI: 10.3352/jeehp.2006.3.3 PMID: 19223995.

28. Masic I. E-learning as new method of medical education. Acta informatica medica. 2008;16(2):102. DOI: 10.5455/ aim.2008.16.102-117 